\title{
Community-Level Response of Fishes and Aquatic Macroinvertebrates to Stream Restoration in a Third-Order Tributary of the Potomac River, USA
}

\author{
Stephen M. Selego, ${ }^{1,2}$ Charneé L. Rose, ${ }^{1,3}$ George T. Merovich Jr., \\ Stuart A. Welsh, ${ }^{4}$ and James T. Anderson ${ }^{1,5}$ \\ ${ }^{1}$ Wildlife and Fisheries Resources Program, Division of Forestry and Natural Resources, West Virginia University, \\ P.O. Box 6125, Percival Hall, Morgantown, WV 26506, USA \\ ${ }^{2}$ Department of Fisheries and Wildlife, Oregon State University, Corvallis, Oregon 97331, USA \\ ${ }^{3}$ Department of Forest Ecosystems and Society, Oregon State University, Corvallis, Oregon 97331, USA \\ ${ }^{4}$ U.S. Geological Survey, WV Cooperative Fish and Wildlife Research Unit, West Virginia University, Morgantown, \\ WV 26506, USA \\ ${ }^{5}$ Environmental Research Center, West Virginia University, P.O. Box 6125, Percival Hall, Morgantown, WV 26506, USA
}

Correspondence should be addressed to James T. Anderson, jim.anderson@mail.wvu.edu

Received 15 July 2011; Revised 1 September 2011; Accepted 5 September 2011

Academic Editor: Bradford Hawkins

Copyright (C) 2012 Stephen M. Selego et al. This is an open access article distributed under the Creative Commons Attribution License, which permits unrestricted use, distribution, and reproduction in any medium, provided the original work is properly cited.

\begin{abstract}
Natural stream channel design principles and riparian restoration practices were applied during spring 2010 to an agriculturally impaired reach of the Cacapon River, a tributary of the Potomac River which flows into the Chesapeake Bay. Aquatic macroinvertebrates and fishes were sampled from the restoration reach, two degraded control, and two natural reference reaches prior to, concurrently with, and following restoration (2009 through 2010). Collector filterers and scrapers replaced collector gatherers as the dominant macroinvertebrate functional feeding groups in the restoration reach. Before restoration, based on indices of biotic integrity (IBI), the restoration reach fish and macroinvertebrate communities closely resembled those sampled from the control reaches, and after restoration more closely resembled those from the reference reaches. Although the macroinvertebrate community responded more favorably than the fish community, both communities recovered quickly from the temporary impairment caused by the disturbance of restoration procedures and suggest rapid improvement in local ecological conditions.
\end{abstract}

\section{Introduction}

Riverine ecosystems worldwide are threatened due to exploitation for food and water, pollutant runoff, and alteration of flow regimes $[1,2]$. Such threats may result in the declining biodiversity or extinction of aquatic taxa [3]. As a result, continued stream restoration projects are important to maintain or achieve ecological health at impaired locations. A healthy system is one that can support its current land uses, including agricultural practices, without future ecosystem degradation [4]. Healthy aquatic communities, therefore, are resilient and sustainable in spite of local human influence. Restoration is the process of reversing negative human influences on a system[5], although different restoration techniques have different effects on aquatic community health [6]. In-stream structures such as root wads and log vanes that create scour pools increase habitat heterogeneity, which is important to maintain high diversity of fishes and macroinvertebrates [7,8]. Riparian buffers reduce sediment and pollutant (nitrogen, phosphorous, etc.) input from nonpoint sources, which can negatively impact macroinvertebrate diversity and abundance [9-12]. Buffers of woody vegetation also reduce water temperature and provide a constant supply of organic matter for macroinvertebrates $[10,13,14]$. Aquatic communities also respond differently to temporary disturbances; aquatic community biomass and richness may require as little as 2 months or greater than a year to recover [15]. 
The functional composition of benthic macroinvertebrate communities provides a separate measure of system recovery and health. While the dominant functional feeding groups often vary with stream size (e.g., collector filterers are dominant in most mid-sized rivers [16]), stream quality greatly influences composition. Shredders are more common in streams with forested riparia (sources of coarse particulate organic matter), and collector-gatherer abundance increases with fine particulate organic matter (including cattle feces and the accompanying bacteria) [17]. The abundance of scrapers, most common in mid-sized rivers, reflects the productivity of a specific reach [18].

Natural stream channel design (NSCD) uses restoration techniques to return the project reach to a natural condition, defined by criteria present in a second reach (the "reference reach", a stream of similar gradient, entrenchment ratio, and so forth, but with qualities that prevent it from aggrading or degrading over time) [20]. Successful NSCD improves the physical (e.g., bank stability, water temperature), chemical (e.g., nitrogen and phosphorus inputs), and biological (e.g., biodiversity, biomass) conditions of the reach [21] and results in conditions capable of water and sediment transport without significant structural change [22]. Ultimately, the goal is to create stream conditions that will remain at a natural state without human assistance [21].

To further our understanding of restoration practices and improve the success of future projects, it is important to measure the effectiveness of past projects $[11,23]$. Unfortunately, postproject evaluation is rare $[6,24]$. Long-term effects may also take years to manifest $[25,26]$. Our overall project goals were to measure the response of aquatic biota to in-stream and stream-bank restoration techniques following NSCD principles in a third-order stream in the Chesapeake Bay Watershed, USA. Specifically, our research objectives were to: (1) quantify the biotic conditions of the fish and macroinvertebrate communities in response to restoration using indices of biotic integrity; (2) determine the effects of restoration on the functional composition of the macroinvertebrate community; (3) analyze the community-level responses of macroinvertebrates and fishes to restoration. If the restoration was successful, we expected the postrestoration aquatic communities to resemble those of the natural reference reaches more closely than those of the degraded control reaches (in terms of IBI scores, functional composition, and taxonomic composition). Thus, we hypothesized that IBI scores, functional composition, and taxonomic composition at the restoration reach would be similar to degraded control reaches prior to restoration and transition towards natural reference reaches following restoration.

\section{Methods}

2.1. Study Site. We conducted our study in the Cacapon River, a wide, shallow third-order tributary of the Potomac River located in the Eastern panhandle of WVa, USA. This area is part of the Ridge-and-Valley physiographic province [27]. The climate is humid continental, with hot summers and year-round precipitation totaling about $91 \mathrm{~cm}$ annually [28]. The hills above the river are composed predominantly of sandstone [29]. The river has an average $\mathrm{pH}$ of 8.1, water temperature of $23.2^{\circ} \mathrm{C}$, and phosphate concentration of $0.033 \mathrm{mg} / \mathrm{L}$. In areas of agricultural activity, heavy rains cause substantial $(\geq 2,000 \mathrm{cfs})$ increases in river discharge and accompanying spikes in fecal coliform concentrations. Such contamination is especially common between March and May. American eels (Anguilla rostrata) have been detected within the river, having migrated from the Chesapeake Bay.

Stream restoration was conducted on one $500 \mathrm{~m}$ reach of the river, selected based on a modified rating system to prioritize restoration efforts [30]. This system ranks potential reaches based on degradation level (quantified using rapid visual habitat assessment and the Rosgen classification system [20]), anticipated restoration costs, and landowner cooperation. Most of this reach was used as pastureland for cattle; a small percentage was forested. Prior to restoration, both banks were nearly vertical and were being removed by the river at a rate of up to one meter per year (unpublished data, Jonathan L. Pitchford).

In addition to the restoration reach, four additional reaches were selected for sampling (see Appendix I in Supplementary Material available online at doi: 10.1155/2012/ 753634). Two were agriculturally impaired control reaches (stream bank impairments similar to the restoration reach) not receiving restoration, and two were natural reference reaches with stable (not actively eroding) banks and diverse in-stream habitat. One of each of the two reach categories was located upstream of the restoration reach, and one was downstream, each no more than four $\mathrm{km}$ from the restoration reach. Each reach was $120 \mathrm{~m}$ long, corresponding to the shortest wadeable distance of any of the reaches. Reaches were selected based on rapid visual habitat assessment (RVHA) scores for high-gradient streams [31], with control reaches (139 and 136) having similar scores to the restoration reach (136) and reference reaches (152 and 163) scoring higher than the restoration reach (Appendix II). Values range from 0 to 200, with scores above 160 considered "optimal". Each of the reaches was assumed to have similar water chemistry due to similar land use and the absence of major sources of pollutant influx between the reaches.

The riparian zones of the reference reaches were dominated by tree species, including American sycamore (Platanus occidentalis) and tulip poplar (Liriodendron tulipifera), with interspersed grasses and forbs. The riparian zones of the two control reaches had fewer trees and more grasses, such as reed canary grass (Phalaris arundinacea), and in many areas were actively grazed by cattle.

2.2. Restoration Methods. Project personnel and Canaan Valley Institute (Davis, WVa) organized multiple in-stream and stream-bank restoration techniques for the restoration reach of the Cacapon River during the spring of 2010. Log vanes were constructed at nine locations within the reach. Gravel was deposited downstream of the log vanes to create riffle and run features beyond the scour pools created by the vanes. The vanes were angled to minimize erosive pressure on the associated banks. 
Both banks were recontoured by Red Creek Enterprises (excavation company, Dry Fork, WVa) and planted with native warm-season grasses, pollinator strips, and native saplings to begin establishment of riparian buffers (Appendix III). Woody plantings were predominantly pin oak (Quercus palustris), swamp white oak (Q. bicolor), black willow (Salix nigra), and buttonbush (Cephalanthus occidentalis). The planted areas were further protected with burlap mesh and coconut-fiber biologs and lined with electric fence, installed by Bland Fencing LLC (Petersburg, $\mathrm{WVa})$, to prevent access by cattle and white-tailed deer (Odocoileus virginianus). During the fall of 2010, we removed invasive species (barberry, Berberis thunbergii; autumn olive, Elaeagnus umbellate; multiflora rose, Rosa multiflora) from the riparian zone using a "hack " $n$ " squirt" method with Roundup herbicide (Monsanto Co., St. Louis, Mo, United States). Roundup is a broad-spectrum herbicide, which uses the active ingredient glyphosate.

2.3. Sampling Methods. We collected aquatic macroinvertebrates from the Cacapon River during July 2009 and March 2010 (Summer and Winter, both before restoration), May 2010 (during active restoration), and July 2010 (following restoration). We took six kick samples from riffles in each of the five study reaches, and composited them as one sample per reach. Riffles were selected to represent the varying depths and water velocities in the reach. Each kick sample was a complete disturbance of a square meter area upstream of a $1 \times 1 \mathrm{~m}$ hand screen $(500 \mu \mathrm{m}$ mesh $)$ for one minute. Afterwards, large objects such as rocks and woody debris within the square meter sample area were scraped by hand to dislodge any additional macroinvertebrates. All material trapped in the net after each sample was transferred to 95\% ethanol and identified in the lab to genus level or lowest taxonomic level possible [31-33].

We collected fishes from each study reach during August 2009 (before restoration) and August 2010 (after restoration) (ACUC protocol number: 090407). An additional sample was collected from the restoration reach and both control reaches during active restoration in May 2010. Two researchers, each with an electrofishing unit (Smith-Root, Inc., Vancouver, Wash), made one simultaneous upstream pass (standardized to 45 minutes per reach) through each sampling reach, terminating at a shallow riffle to prevent continued upstream movement of the fishes [31, 34]. All identified individuals were released on site. Unidentified specimens were anesthetized and euthanized in pharmaceutical grade MS-222, fixed in 10\% formalin solution, and identified to species in the lab [35].

2.4. Data Analysis. To address our first objective, we used multimetric indices of biotic integrity (IBI) to quantify the biological conditions of fishes and macroinvertebrate communities in response to restoration practices. For macroinvertebrates, our IBI included individual family-level metrics from the WVa Stream Condition Index (WVSCI) [36]: total taxa richness; total Ephemeroptera, Plecoptera, and Trichoptera (EPT) richness; percent of sample composed of EPT; percent of sample composed of Chironomidae; and Hilsenhoff Biotic Index [37]. Three additional metrics were added to construct the final eight-metric index: total genus richness, total abundance, and percent of sample composed of two most dominant taxa (genus-level for nonChironomid insects, family for other taxa) $[36,38,39]$. The Hilsenhoff Biotic Index (HBI) is calculated by multiplying each taxon's tolerance value (low for intolerant taxa, high for tolerant taxa) by its proportion in the sample, then summing these products.

Within each sampling season, the five reaches were ranked (1-5, 5 indicating the highest IBI metric and healthiest reach) for each of the eight metrics. Reaches with tied values within a metric each received the average of the integer ranks that would be assigned to those sites. The sum of these ranks was calculated for each reach and each sampling season, and is here denoted as "IBI rank sums." The rank sums within a sampling season are not independent (they are constrained to a total value of 120 across all reaches within the season). Therefore, they represent comparative community health and are not interpretable when considered separately.

We quantified fish community health using an IBI developed by Daniels et al. [19] for Mid-Atlantic drainages. The individual metrics included: total species richness, benthic insectivorous species richness, water column species richness, terete minnow species richness, percent dominant species, percent Catostomus commersoni (white sucker), percent per trophic guild (generalist, insectivore, top predator), individuals per sample, percent juveniles, and percent with anomalies (injuries, torn fins, deformities, and excessive parasites). Each metric is scored 1, 3, or 5 (5 indicating ideal conditions) and summed to create an overall score for the reach.

For our second objective, to measure the effect of restoration on macroinvertebrate functional ecology, we placed each genus into one of five functional feeding groups (FFG): collector gatherer, collector filterer, predator, scraper, and shredder [39]. The proportion of each group in each sample was calculated. When multiple possible FFGs were identified for a particular genus (or higher taxonomic level, when genus level was not reached) across multiple species, we used the most commonly occurring classification.

Finally, to address our third objective, we used nonmetric multidimensional scaling (NMDS) to summarize fish and macroinvertebrate community structure in relation to the restoration reach (control versus reference versus pre- and postrestoration). We ran NMDS once using the macroinvertebrate community data from the summers before (2009) and after (2010) restoration efforts, and again using the summer 2009 and summer 2010 fish community data. NMDS is an unconstrained ordination technique that maps samples in reduced dimensional space using only the rank order of dissimilarity values among samples. It is an attractive analytical technique because it does not require multivariate normality [40]. We used the Bray-Curtis distance metric for both communities, on double transformation of the abundance data [41]. The NMDS solutions were determined in two, three, and four dimensions using multiple random starts to maximize the likelihood of reaching a global minimum stress value, but only the two-dimensional solution was retained 
because stress did not decline appreciably with additional dimensions. To interpret the gradient structure of the macroinvertebrate and fish community ordination, we used vector fitting to correlate (Pearson's coefficient) community metrics to the corresponding NMDS ordination. Statistical significance of these correlations was evaluated with 1000 permutations of the data. We also plotted the weighted average positions of several selected taxa in ordination space. Family-level data were used instead of genera data for macroinvertebrates in order to standardize the display of insect and non-insect taxa.

To determine the statistical differences of our groupings in NMDS space, we conducted permutational multivariate analyses of variance (PERMANOVA) separately on the macroinvertebrate and fish community data using the BrayCurtis distance metric (Bray-Curtis) [42]. Initially, we ran a PERMANOVA for each community using data from the summers of 2009 and 2010, comparing the control to the reference reaches. We followed this test with four individual PERMANOVAs (using the same 2009 and 2010 data) labeling the pre- and postrestoration reaches as either control or reference reach replicates. We expected the prerestoration reach to resemble a control reach and the postrestoration reach to resemble a reference reach based on NMDS, so the first PERMANOVA labeled the prerestoration reach as a control replicate and the postrestoration reach as a reference replicate. The other three tests consisted of the additional combinations: pre as a control and post as a control, pre as a reference and post as control, and pre as a reference and post as a reference. We then compared the $P$ values (generated from 1000 permutations of the data) obtained from each of the four additional tests to determine if the pre- and postrestoration reaches were each more similar to either control or reference reaches. Reach categories were replicated across seasons (2009 and 2010) and spatial arrangements (upstream and downstream). Since PERMANOVA does not require multivariate normality, the data were not transformed [40]. We conducted all analyses in the $\mathrm{R}$ language and environment for statistical computing ( $\mathrm{R}$ Development Core Team 2011). We used library vegan with function metaMDS for NMDS, function envfit for vector fitting, and function adonis for PERMANOVA [41].

\section{Results}

3.1. Macroinvertebrate Community Assessment. A total of 30,487 individual aquatic macroinvertebrates representing 66 families and 99 genera were collected from the five study reaches across four sampling seasons (Appendix IV). Thirty of the 66 families were EPT orders, totaling 51.5\% of individuals. Stenelmis (riffle beetle, Elmidae) was the most commonly collected and composed $14.5 \%$ of the individuals. Nonbiting midges (Chironomidae) composed $10.8 \%$ of individuals.

Of the eight macroinvertebrate IBI metrics, three (total genus richness, total family richness, and Hilsenhoff Biotic Index value) scored higher in reference reaches than control reaches during all four sampling seasons. Two additional

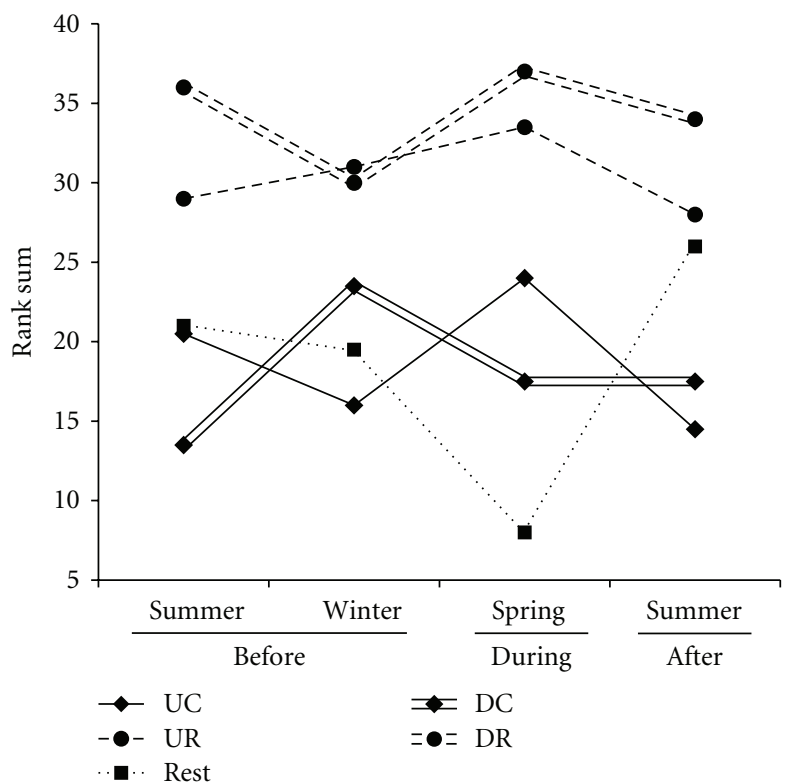

FIgURE 1: Cacapon River, WVa, USA restoration, control, and reference sampling reach rank sum scores for macroinvertebrate modified index of biotic integrity (IBI) across all sampling seasons: before (two samples, 2009-2010), during (2010), and after (2010) restoration. Higher scores indicate healthier communities based on the metrics measured. Upstream control (impaired reach, but not receiving restoration) denoted "UC", downstream control denoted "DC", upstream reference (unimpaired, natural reach) denoted "UR", and downstream reference denoted "DR". The restoration reach is denoted as "Rest".

metrics (percent EPT and percent Chironomidae) scored higher in references than controls during three of the four seasons. Macroinvertebrate abundance was not always higher in the reference reaches than in the control reaches. However, abundance increased greatly at the restoration reach following restoration and was far higher in the postrestoration reach than in any other sample. Stenelmis, Corydalus (hellgrammite), and aquatic mollusk genera (Pseudosuccinea, Leptoxis) were considerably more abundant than in pre- and during restoration samples. Corbicula, an invasive Asiatic clam, also increased in abundance following restoration.

During all four sampling seasons, the two reference reaches had higher IBI rank sum scores (RSS) than the two control reaches (Figure 1). During restoration, the restoration reach ranked worst on all 8 individual metrics for the season. Following restoration, the restoration reach RSS was closer to the reference reach scores than to the control reach scores.

In terms of macroinvertebrate community composition, NMDS showed that the prerestoration reach was more similar to control reaches, and the postrestoration reach was more similar to reference reaches (Figure 2). PERMANOVA detected statistical difference between the control and reference reaches $\left(F_{[1,5]}=5.91, P=0.028\right)$. The lowest $P$ value associated with the four additional PERMANOVAs was generated from labeling the prerestoration as a control 


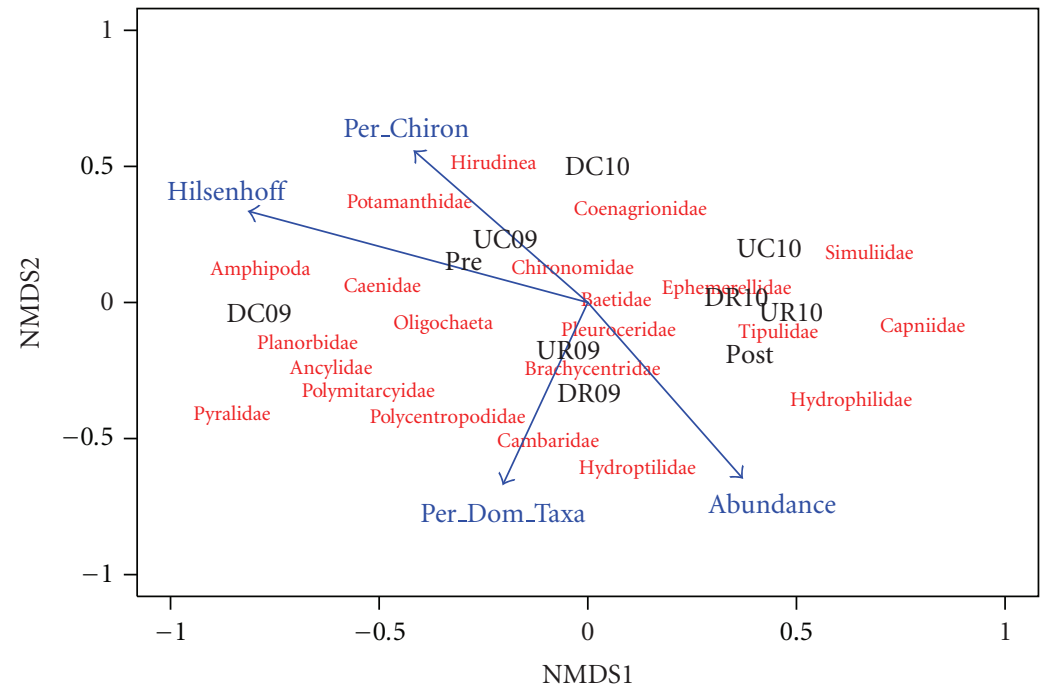

FIGURE 2: Nonmetric multidimensional scaling (NMDS) ordination plot for aquatic macroinvertebrate communities at all sampling reaches (stress $=10.6$ for 2-dimensional solution) in the Cacapon River, WVa, USA. Reaches are labeled by reach category: upstream control (impaired reach, but not receiving restoration) denoted "UC"; downstream control denoted "DC"; upstream reference (unimpaired, natural reach) denoted "UR"; and downstream reference denoted "DR". "Pre" denotes the restoration reach prior to restoration (2009), and "Post" denotes the restoration reach after restoration (2010). Selected macroinvertebrate taxa are positioned in the ordination as weighted averages. Vector lengths indicate relative correlative strength of macroinvertebrate community metrics $(P \leq 0.05 ; 1000$ permutations).

TAble 1: Significant Pearson's correlation coefficients and associated permutational $P$ values (1000 randomizations) for relations between fish Daniels et al. [19] and macroinvertebrate indices of biotic integrity metrics and nonmetric multidimensional scaling (NMDS) ordination for the communities sampled during the summers of 2009 and 2010 from the Cacapon River, WVa, USA.

\begin{tabular}{llcc}
\hline Community & Metric & Vector $r^{2}$ & $P$ value \\
\hline Macroinvertebrate & Percent chironomidae & 0.580 & 0.044 \\
& Percent dominant 2 taxa & 0.584 & 0.040 \\
& Hilsenhoff Biotic Index & 0.931 & 0.001 \\
Fish & Abundance & 0.664 & 0.025 \\
\hline
\end{tabular}

replicate and the postrestoration as a reference replicate $\left(F_{[1,6]}=8.20, P=0.001\right)$, suggesting the restoration reach became more similar to a natural reach following restoration. The other three combinations produced higher $P$ values: pre and post as references $\left(F_{[1,6]}=4.85, P=0.019\right)$, pre and post as controls $\left(F_{[1,6]}=2.98, P=0.051\right)$, and pre as a reference and post as a control $\left(F_{[1,6]}=1.77, P=0.175\right)$. Four metrics (Hilsenhoff Index value, abundance, percent dominant taxa, and percent Chironomidae) were strongly correlated with the NMDS solution (Table 1, Appendix V). Percent EPT was the least correlated. Control reaches and the prerestoration reach were associated with several non-insect taxa (Hirudinea, Amphipoda, Planorbidae) in ordination space, whereas reference reaches and the postrestoration reach were located near the weighted averages of taxa typically considered indicators of excellent ecological conditions (e.g., Tipulidae, Ephemerellidae, and Brachycentridae) (Figure 2). Therefore, the reference reaches appear ecologically diverse and healthy, and the restoration procedures improved the restoration reach to a similar capacity.
Across all study reaches and sampling seasons, scrapers were the most abundant FFG with 10,196 individuals (33.4\% of individuals). Shredders made up $2.0 \%$ of individuals and were the least represented FFG. Before restoration efforts (during both summer and winter sampling seasons) and during restoration, collector gatherers were the most dominant feeding group at the restoration reach. Following restoration efforts, collector filterers and scrapers became the most dominant groups at the restoration reach (Figure 3).

3.2. Fish Community Assessment. Overall, 33 fish species and 2,305 individuals were collected from the study reaches (Appendix VI). Bluntnose minnows (Pimephales notatus, $40.5 \%$ of individuals), redbreast sunfish (Lepomis auritus, $10.5 \%$ ), rosyface shiners (Notropis rubellus, 8.1\%), and tessellated darters (Etheostoma olmstedi, 7.6\%) were the most common species. The reference reaches had higher IBI scores than the control reaches and the restoration reach both prior to and following restoration (Figure 4). During restoration, the restoration reach scored lower than all other reaches. The 


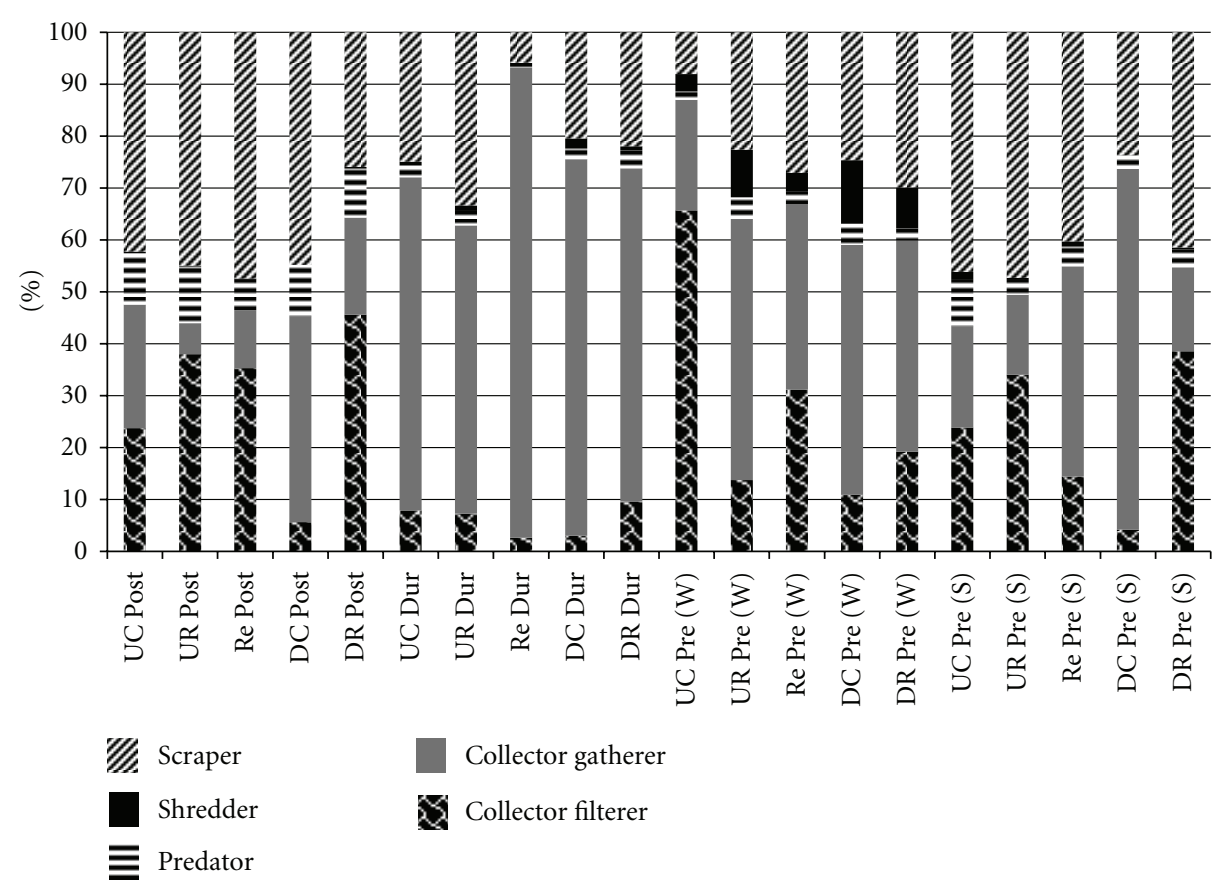

FIGURE 3: Proportions of functional feeding groups present at each reach in the Cacapon River, WVa, USA during each sampling season. Upstream control (impaired reach, but not receiving restoration) denoted "UC", downstream control denoted "DC", upstream reference (unimpaired, natural reach) denoted "UR", and downstream reference denoted "DR". The restoration reach is denoted as "Re". "Post" refers to postrestoration samples (2010), "Dur" refers to during restoration samples (2010), and "Pre" refers to prerestoration samples from summer 2009 (S) and winter 2010 (W).

reference reaches scored higher than the control reaches for "total terete minnows" and "percent juvenile and adult" after restoration. Both references did not score higher than the control reaches on any individual metric before restoration.

In terms of fish community composition, the pre- and postrestoration conditions appeared similar to both control and reference reaches (Figure 5). Interestingly, only the percent of anomalies was correlated $\left(r^{2}=0.71, P<0.001\right)$ with the NMDS solution (Table 1). These anomalies were generally excessive parasites (especially black spot disease) and torn fins, and the control reaches had greater than $5 \%$ of individuals with these anomalies both before and after restoration. No species had strong association with reach categories in ordination space, suggesting that the fish communities were relatively similar between the categories. PERMANOVA indicated that fish community composition did not differ statistically between control and reference reaches $\left(F_{[2,4]}=1.02, P=0.455\right)$. However, the lowest $P$ value was obtained from labeling the prerestoration as a control replicate and the postrestoration as a reference replicate $\left(F_{[1,6]}=1.80, P=0.130\right)$. Again, the other three combinations produced higher $P$ values: pre and post as references $\left(F_{[1,6]}=1.05, P=0.337\right)$, pre and post as controls $\left(F_{[1,6]}=0.87, P=0.477\right)$, and pre as a reference and post as a control $\left(F_{[1,6]}=0.91, P=0.440\right)$.

\section{Discussion}

We documented improved health of the macroinvertebrate community less than three months after completion of restoration procedures; however, this improvement was not observed in the fish community. In the years following restoration, the rate of fish and macroinvertebrate community recovery is largely determined by dispersal rather than survival or recruitment [43]. Because many macroinvertebrate species have winged adults, suitable conditions for aerial recolonization may allow rapid recovery of the macroinvertebrate community $[44,45]$. Stenelmis (riffle beetle, Elmidae), the most common macroinvertebrate in the Cacapon, was relatively uncommon at the restoration reach prior to restoration, but was about three times more abundant than any other taxon after restoration. Therefore, conditions were likely suitable for oviposition by this taxon at the restoration reach [46]. Because riffle beetle abundance responds negatively to sedimentation and organic pollution (such as waste from cattle) [17], the persistence of this taxon in future samples may suggest successful restoration of the reach. The Hilsenhoff Biotic Index, which assesses pollution tolerance of the community as a whole [37], should show corresponding improvement.

While fish communities are also known to recover quickly [47], their inability to circumvent in-stream barriers may have led to their delayed recolonization in our study. Additionally, fishes are stronger indicators of large-scale factors affecting stream health than are macroinvertebrates [48]. If the river upstream and downstream of the restoration reach remained impaired in similar ways to past years, this would also affect the ability of the adjacent communities to recolonize the restoration reach. Bluntnose minnows and yellow bullheads (Ameiurus natalis), the most common fish 


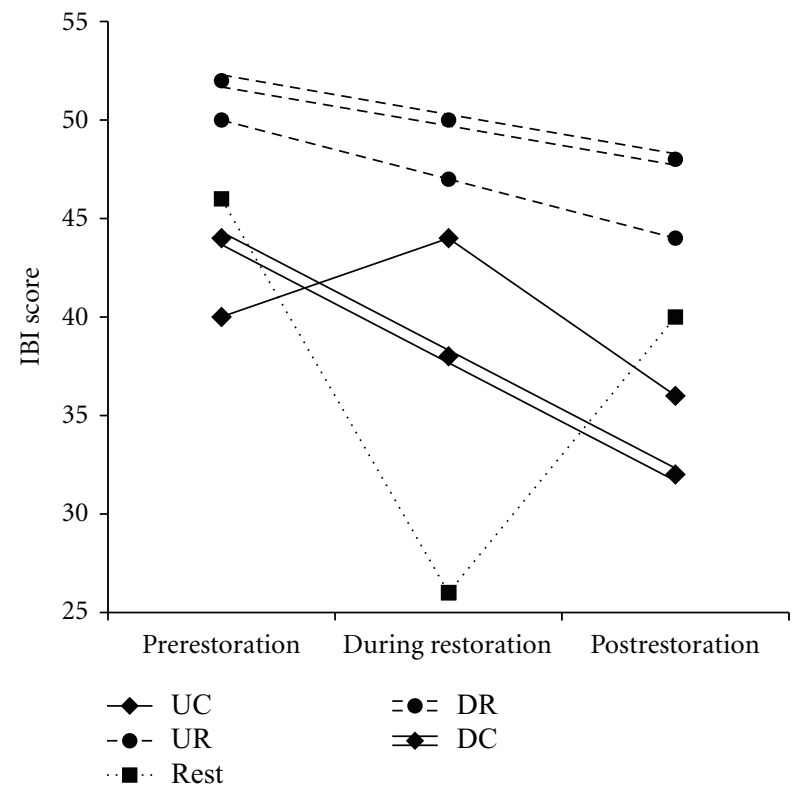

FIgURE 4: Fish community Index of Biotic Integrity scores for restoration, control, and reference reaches in the Cacapon River, WVa, USA based on an index suggested by Daniels et al. [19] Higher IBI scores indicate healthier communities. Upstream control (impaired reach, but not receiving restoration) denoted "UC", downstream control denoted "DC", upstream reference (unimpaired, natural reach) denoted "UR", and downstream reference denoted "DR". The restoration reach is denoted as "Rest". Fishes were sampled before restoration (2009), during restoration (2010), and after restoration (2010).

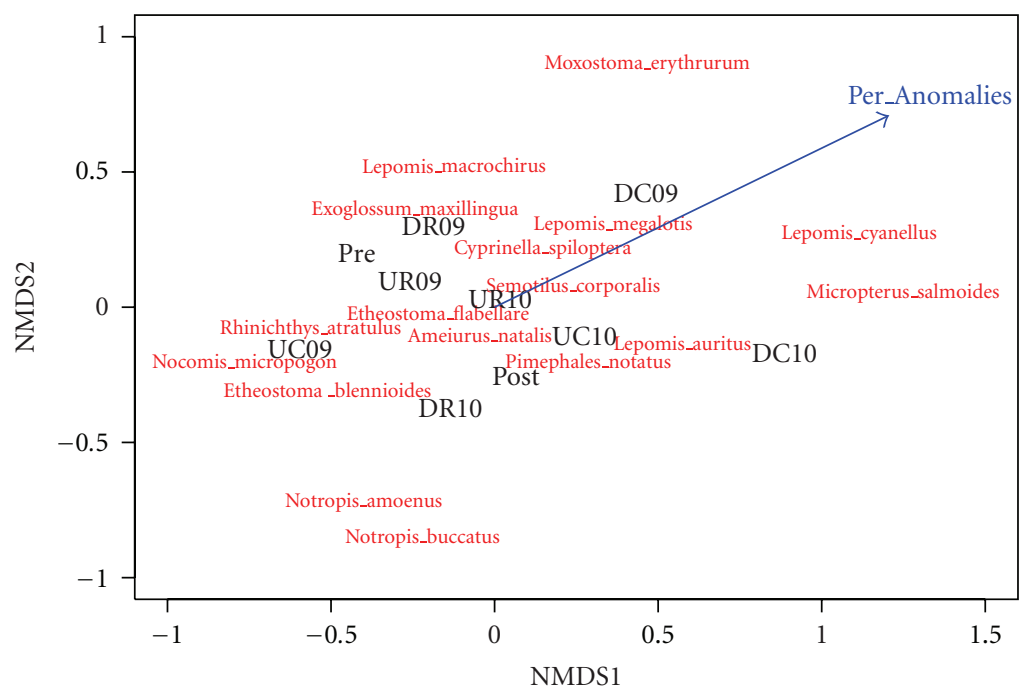

Figure 5: Nonmetric multidimensional scaling (NMDS) ordination plot for fish communities at all sampling reaches (stress $=11.3$ for 2dimensional solution) in the Cacapon River, WVa, USA. Reaches are labeled by reach category: upstream control (impaired reach, but not receiving restoration) denoted "UC"; downstream control denoted "DC"; upstream reference (unimpaired, natural reach) denoted "UR"; downstream reference denoted "DR". "Pre" denotes the restoration reach prior to restoration (2009), and "Post" denotes the restoration reach after restoration (2010). Selected fish species are positioned in the ordination as weighted averages. Vector lengths indicate relative correlative strength of fish community metrics based on an index of biotic integrity suggested by Daniels et al. [19] $(P \leq 0.05 ; 1000$ permutations).

in the postrestoration reach, are sediment-tolerant species [46] that may have persisted in the reach even during implementation of procedures.

Restoration, while ultimately seeking to improve ecological conditions, may be initially harmful to the local communities in similar ways to other disturbances $[48,49]$.
The communities, therefore, must recover from this initial impairment before improvements can be detected. Following restoration, macroinvertebrate abundance reaches maximum levels more quickly than diversity and may be a better indicator of recovery [47]. In our study, macroinvertebrate abundance improved dramatically from prerestoration levels 
and was far higher in the postrestoration reach than in any other sample. Other studies have observed similar increases in abundance following restoration efforts $[50,51]$. Although the fish community in the postrestoration reach was similar to the prerestoration reach, it increased considerably in abundance and species richness compared to the sample during restoration.

In addition to short-term changes in macroinvertebrate abundance at the restoration reach, there was a noticeable shift in the functional composition of the community. Following restoration, collector filterers and scrapers became more common, although the proportion of predators remained quite low. The relative rarity of predators suggests that the macroinvertebrate community was too immature to support higher trophic levels, which in turn could reduce the health of lower trophic levels [52]. However, the ideal proportion of each functional feeding group (FFG) in a community is a subject of debate [39].

In the long term, as seasonal high flows allow recolonization across natural barriers, the local communities should reflect improved biological conditions. Therefore, future surveys are necessary to determine the lasting effects of the restoration efforts. Although macroinvertebrates responded more quickly to restoration than did fishes, the rapid recovery of both communities from the disturbance of restoration (only 3 months following procedures) indicates promising improvements in the health of the local aquatic communities.

\section{Acknowledgments}

Funding and logistical support were provided by the National Fish and Wildlife Foundation, The Chesapeake Bay Trust, National Oceanic and Atmospheric Administration, FishAmerica Foundation, Canaan Valley Institute, and the Cacapon and Lost Rivers Land Trust. Thanks to the local landowners for making this project possible, and Jonathon Pitchford, Crissa Cooey, Tristan Gingerich, and Katy and Noah McCoard for field assistance. This is scientific paper 3115 of the WVa University Agricultural and Forestry Experiment Station.

\section{References}

[1] D. Dudgeon, A. H. Arthington, M. O. Gessner et al., "Freshwater biodiversity: importance, threats, status and conservation challenges," Biological Reviews of the Cambridge Philosophical Society, vol. 81, no. 2, pp. 163-182, 2006.

[2] M. Dynesius and C. Nilsson, "Fragmentation and flow regulation of river systems in the northern third of the world," Science, vol. 266, no. 5186, pp. 753-762, 1994.

[3] A. Ricciardi and J. B. Rasmussen, "Extinction rates of North American freshwater fauna," Conservation Biology, vol. 13, no. 5, pp. 1220-1222, 1999.

[4] J. R. Karr, "Ecological integrity and ecological health are not the same," in Engineering within Ecological Constraints, P. Schulze, Ed., pp. 97-109, National Academy of Engineering. National Academy Press, Washington, DC, USA, 1995.

[5] J. Van Andel and J. Aronson, Eds., Restoration Ecology: The New Frontier, Blackwell, Oxford, UK, 2006.
[6] G. G. Alexander and J. D. Allan, "Ecological success in stream restoration: case studies from the midwestern United States," Environmental Management, vol. 40, no. 2, pp. 245-255, 2007.

[7] P. A. Johnson, R. D. Hey, E. R. Brown, and D. L. Rosgen, "Stream restoration in the vicinity of bridges," Journal of the American Water Resources Association, vol. 38, no. 1, pp. 5567, 2002.

[8] R. R. Radspinner, P. Diplas, A. F. Lightbody, and F. Sotiropoulos, "River training and ecological enhancement potential using in-stream structures," Journal of Hydraulic Engineering, vol. 136, no. 12, pp. 967-980, 2010.

[9] B. W. Sweeney, T. L. Bott, J. K. Jackson et al., "Riparian deforestation, stream narrowing, and loss of stream ecosystem services," Proceedings of the National Academy of Sciences of the United States of America, vol. 101, no. 39, pp. 14132-14137, 2004.

[10] B. M. Teels, C. A. Rewa, and J. Myers, "Aquatic condition response to riparian buffer establishment," Wildlife Society Bulletin, vol. 34, no. 4, pp. 927-935, 2006.

[11] S. W. Miller, P. Budy, and J. C. Schmidt, "Quantifying macroinvertebrate responses to in-stream habitat restoration: applications of meta-analysis to river restoration," Restoration Ecology, vol. 18, no. 1, pp. 8-19, 2010.

[12] D. R. Lenat, "Agriculture and stream water quality: a biological evaluation of erosion control practices," Environmental Management, vol. 8, no. 4, pp. 333-343, 1984.

[13] J. J. Opperman and A. M. Merenlender, "The effectiveness of riparian restoration for improving instream fish habitat in four hardwood-dominated California streams," North American Journal of Fisheries Management, vol. 24, no. 3, pp. 822834, 2004.

[14] R. F. Carline and M. C. Walsh, "Responses to riparian restoration in the Spring Creek watershed, Central Pennsylvania," Restoration Ecology, vol. 15, no. 4, pp. 731-742, 2007.

[15] J. C. Coleman, M. C. Miller, and F. L. Mink, "Hydrologic disturbance reduces biological integrity in urban streams," Environmental Monitoring and Assessment, vol. 172, no. 1-4, pp. 663-687, 2010.

[16] C. P. Hawkins and J. R. Sedell, "Longitudinal and seasonal changes in functional organization of macroinvertebrate communities in four Oregon streams," Ecology, vol. 62, pp. 387397, 1981.

[17] A. Braccia and J. R. Voshell, "Benthic macroinvertebrate responses to increasing levels of cattle grazing in blue ridge mountain streams, Virginia, USA," Environmental Monitoring and Assessment, vol. 131, no. 1-3, pp. 185-200, 2007.

[18] R. L. Vannote, G. W. Minshall, K. W. Cummins, J. R. Sedell, and C. E. Cushing, "The river continuum concept," Canadian Journal of Fisheries and Aquatic Sciences, vol. 37, no. 1, pp. 130137, 1980.

[19] R. A. Daniels, K. Riva-Murray, D. B. Halliwell, D. L. VanaMiller, and M. D. Bilger, "An index of biological integrity for northern Mid-Atlantic Slope drainages," Transactions of the American Fisheries Society, vol. 131, no. 6, pp. 1044-1060, 2002.

[20] D. L. Rosgen, "The reference reach-a blueprint for natural channel design," in Proceedings of the American Society of Civil Engineers, Restoration of Wetlands and Rivers, Denver, Colo, USA, 1998.

[21] Keystone Stream Team, Guidelines for Natural Stream Channel Design for Pennsylvania Waterways. Alliance for Chesapeake Bay and Pennsylvania Department of Environmental Protection, Williamsport, Philadelphia, Pa, USA, 2003. 
[22] G. Nagle, “Evaluating 'natural channel design' stream projects," Hydrological Processes, vol. 21, no. 18, pp. 2539-2545, 2007.

[23] A. Selvakumar, T. P. O'Connor, and S. D. Struck, "Role of stream restoration on improving benthic macroinvertebrates and In-stream water quality in an urban watershed: Case study," Journal of Environmental Engineering, vol. 136, no. 1, pp. 127-139, 2010.

[24] G. M. Kondolf and E. R. Micheli, "Evaluating stream restoration projects," Environmental Management, vol. 19, no. 1, pp. $1-15,1995$.

[25] A. H. Moerke, K. J. Gerard, J. A. Latimore, R. A. Hellenthal, and G. A. Lamberti, "Restoration of an Indiana, USA, stream: Bridging the gap between basic and applied lotic ecology," Journal of the North American Benthological Society, vol. 23, no. 3, pp. 647-660, 2004.

[26] B. Spänhoff and J. Arle, "Setting attainable goals of stream habitat restoration from a macroinvertebrate view," Restoration Ecology, vol. 15, no. 2, pp. 317-320, 2007.

[27] R. T. Ryder, R. D. Crangle, M. H. Trippi et al., "Geologic cross section D-D' through the Appalachian Basin from the Findlay Arch, Sandusky County, Ohio, to the Valley and Ridge Province, Hardy County, West Virginia," United States Geologic Survey, Reston, Virginia, 2009.

[28] N. Gilles, Cacapon Institute, High View, West Virginia, March 2009, http://www.cacaponinstitute.org/.

[29] G. Constantz, N. Ailes, and D. Malakoff, Portrait of a River: The Ecological Baseline of the Cacapon River, Pine Cabin Run Ecological Laboratory, High View, WVa, USA, 1995.

[30] M. P. Strager, J. T. Anderson, J. D. Osbourne, and R. Fortney, "A three-tiered framework to select, prioritize, and evaluate potential wetland and stream mitigation banking sites," Wetlands Ecology and Management, vol. 19, pp. 1-18, 2011.

[31] M. T. Barbour, J. Gerritsen, B. D. Snyder, and J. B. Stribling, Rapid Bioassessment Protocols for Use in Streams and Wadeable Rivers: Periphyton, Benthic Macroinvertebrates and Fish, U.S. Environmental Protection Agency, Office of Water, Washington, DC, USA, 2nd edition, 1999.

[32] D. R. Lenat, "Water quality assessment of streams using a qualitative collection method for benthic macroinvertebrates," Journal of the North American Benthological Society, vol. 7, pp. 222-233, 1988.

[33] B. L. Peckarsky, P. R. Fraissinet, M. A. Penton, and D. J. Conklin Jr., Freshwater Macroinvertebrates of Northeastern North America, Comstock Publishing Associates, Ithaca, NY, USA, 1990.

[34] S. M. Adams, W. R. Hill, M. J. Peterson, M. G. Ryon, J. G. Smith, and A. J. Stewart, "Assessing recovery in a stream ecosystem: applying multiple chemical and biological endpoints," Ecological Applications, vol. 12, no. 5, pp. 15101527, 2002.

[35] R. E. Jenkins and N. M. Burkhead, Freshwater Fishes of Virginia, American Fisheries Society, Bethesda, Md, USA, 1994.

[36] J. Gerritsen, J. Burton, and M. T. Barbour, A Stream Condition Index for West Virginia Wadeable Streams, Tetra Tech, Owing Mills, Md, USA, 2000.

[37] W. L. Hilsenhoff, "Rapid field assessment of organic pollution with a family-level biotic index," Journal of the North American Benthological Society, vol. 7, pp. 65-68, 1988.

[38] T. R. Angradi, "Fine sediment and macroinvertebrate assemblages in Appalachian streams: a field experiment with biomonitoring applications," Journal of the North American Benthological Society, vol. 18, no. 1, pp. 49-66, 1999.
[39] S. M. Mandaville, Benthic Macroinvertebrates in FreshwatersTaxa Tolerance Values, Metrics, and Protocols, Soil \& Water Conservation Society of Metro Halifax, Nova Scotia, Canada, 2002.

[40] T. D. Johnson, T. E. Kolb, and A. L. Medina, "Do riparian plant community characteristics differ between Tamarix (L.) invaded and non-invaded sites on the upper Verde River, Arizona?" Biological Invasions, vol. 12, no. 8, pp. 2487-2497, 2010.

[41] J. Oksanen, R. Kindt, P. Legendre et al., Vegan: community ecology package, R package version 1.15-0, 2008.

[42] M. D. Wildsmith, T. H. Rose, I. C. Potter, R. M. Warwick, K. R. Clarke, and F. J. Valesini, "Changes in the benthic macroinvertebrate fauna of a large microtidal estuary following extreme modifications aimed at reducing eutrophication," Marine Pollution Bulletin, vol. 58, no. 9, pp. 1250-1262, 2009.

[43] N. R. Bond and P. S. Lake, "Local habitat restoration in streams: constraints on the effectiveness of restoration for stream biota," Ecological Management and Restoration, vol. 4, no. 3, pp. 193-198, 2003.

[44] T. Muotka, R. Paavola, A. Haapala, M. Novikmec, and P. Laasonen, "Long-term recovery of stream habitat structure and benthic invertebrate communities from in-stream restoration," Biological Conservation, vol. 105, no. 2, pp. 243-253, 2001.

[45] T. J. Blakely, J. S. Harding, A. R. Mcintosh, and M. J. Winterbourn, "Barriers to the recovery of aquatic insect communities in urban streams," Freshwater Biology, vol. 51, no. 9, pp. 1634-1645, 2006.

[46] A. S. Trebitz, B. H. Hill, and F. H. McCormick, "Sensitivity of indices of biotic integrity to simulated fish assemblage changes," Environmental Management, vol. 32, no. 4, pp. 499-515, 2003.

[47] A. H. Moerke, K. J. Gerard, J. A. Latimore, R. A. Hellenthal, and G. A. Lamberti, "Restoration of an Indiana, USA, stream: bridging the gap between basic and applied lotic ecology," Journal of the North American Benthological Society, vol. 23, no. 3, pp. 647-660, 2004.

[48] H. E. Berkman, C. F. Rabeni, and T. P. Boyle, "Biomonitors of stream quality in agricultural areas: fish versus invertebrates," Environmental Management, vol. 10, no. 3, pp. 413-419, 1986.

[49] P. Tikkanen, P. Laasonen, T. Muotka, A. Huhta, and K. Kuusela, "Short-term recovery of benthos following disturbance from stream habitat rehabilitation," Hydrobiologia, vol. 273, no. 2, pp. 121-130, 1994.

[50] M. A. Palmer, E. S. Bernhardt, J. D. Allan et al., "Standards for ecologically successful river restoration," Journal of Applied Ecology, vol. 42, no. 2, pp. 208-217, 2005.

[51] J. B. Wallace, "Recovery of lotic macroinvertebrate communities from disturbance," Environmental Management, vol. 14, no. 5, pp. 605-620, 1990.

[52] E. Nilsson, K. Olsson, A. Persson, P. Nyström, G. Svensson, and U. Nilsson, "Effects of stream predator richness on the prey community and ecosystem attributes," Oecologia, vol. 157, no. 4, pp. 641-651, 2008. 

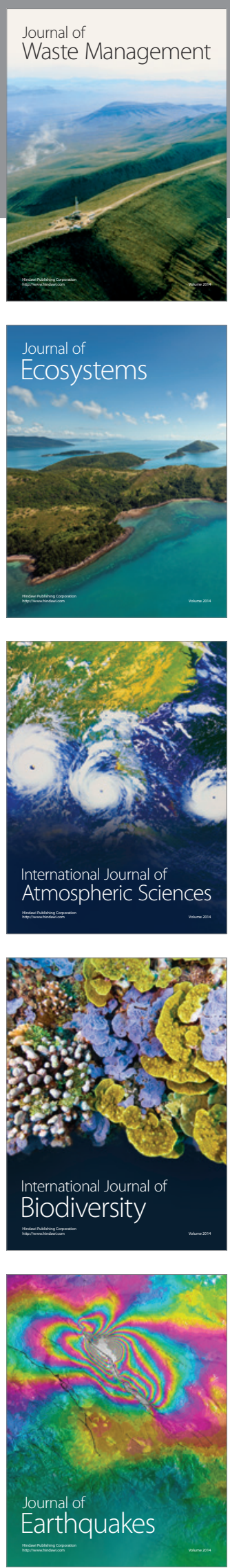
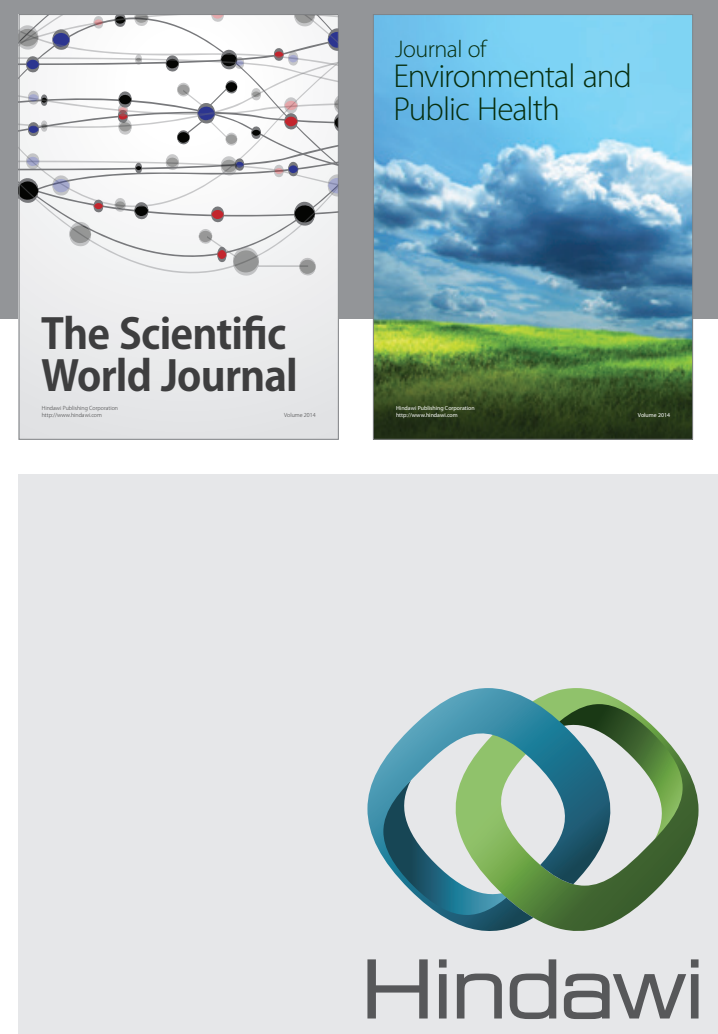

Submit your manuscripts at

http://www.hindawi.com
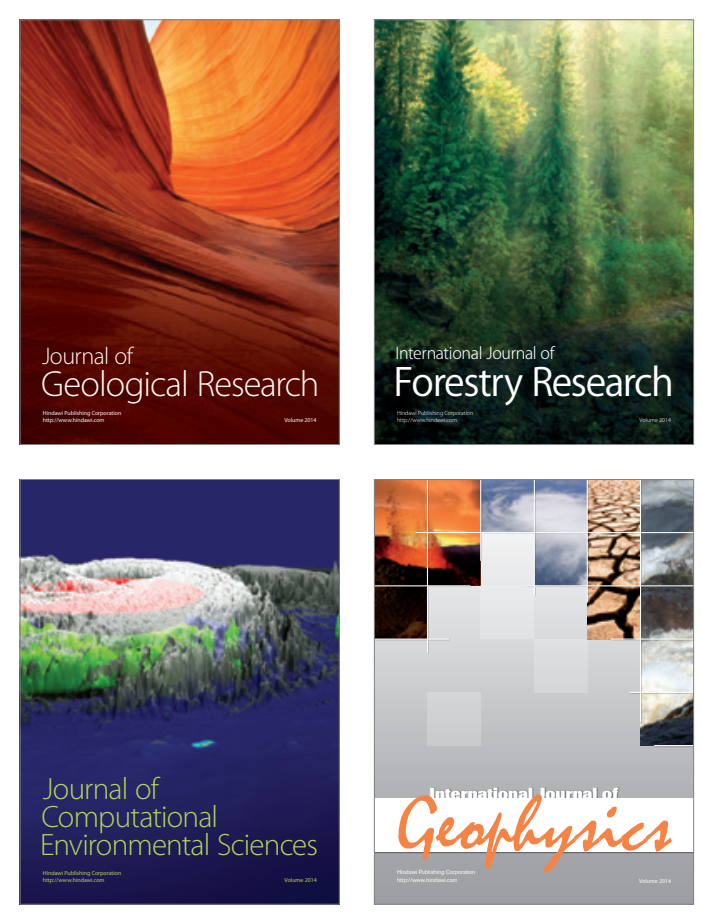
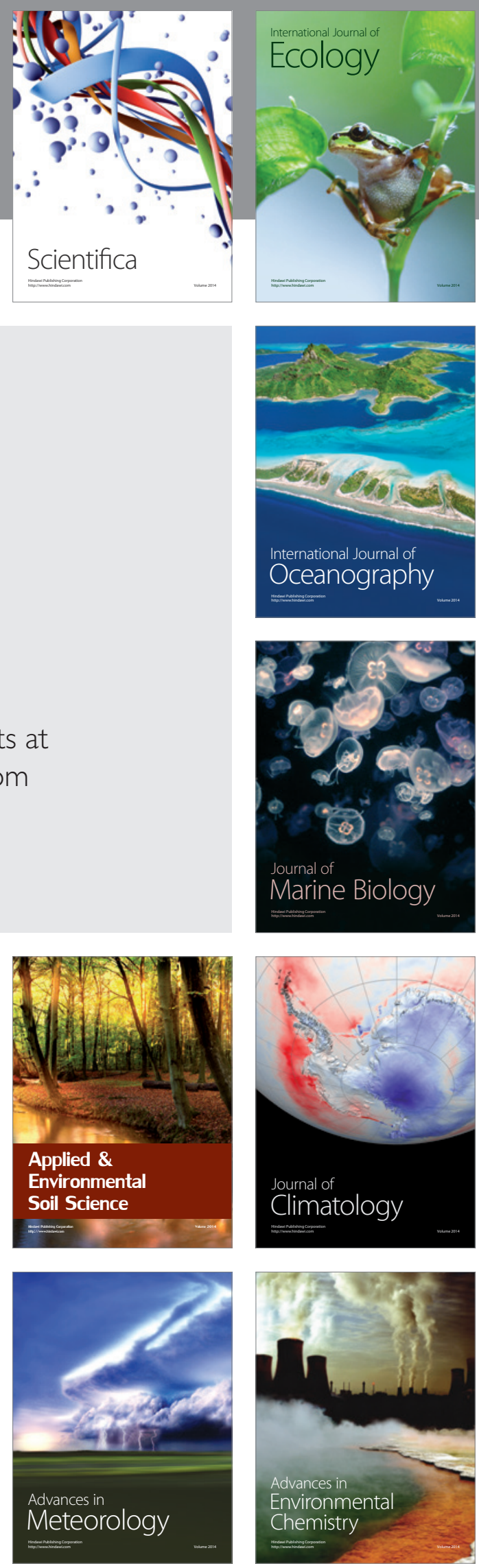